\title{
EFFECTS OF CONCRETE BLOCK PAVEMENT ON FLOW RETARDATION FACTOR
}

\author{
Laksni Sedyowati $^{\text {a, *, Eko Indah Susanti }}{ }^{\text {a }}$ \\ ${ }^{a}$ University of Merdeka Malang, Faculty of Engineering, Civil Engineering Department, Jl. Terusan Raya Dieng 62-64, Malang 65146, Indonesia
}

Received: 16.12.2016 / Accepted: 20.01.2017 / Revised: 06.05.2017 / Available online: 31.05.2017

DOI: 10.1515/jaes-2017-0004

KEY WORDS: sustainable urban drainage system, low impact development, surface runoff, hydrological model, paving blocks

\begin{abstract}
:
Surface roughness has an important role in retarding the runoff velocity. The increase in paving blocks usage, particularly in urban areas, can change the surface roughness of the land. This study investigated the effects of four types of concrete block pavements (CBPs) in retarding the surface runoff velocity. Three design parameters based on CBP properties that considerably influenced the flow retardation were promoted. They were opening ratio (Or), void ratio (Vr) and straight channel ratio (Sr). A tilted plot equipped with a rainfall simulator was used to investigate the influence of surface slope and rainfall intensity to the flow on various CBPs. A modified dye tracing method in view was performed to monitor the surface flow velocity under various rainfall intensities. Flow retardation coefficient (Frd) were calculated based on velocity data on smooth pavement and on CBPs layer measured under the same slope and rainfall intensity. The results showed that flow retardation coefficient increased with an increase in openings ratio, rainfall intensity and surface slope. The relationship between flow retardation coefficient and all design parameters was expressed by a linear regression function. A further study is required to increase the accuracy of the model by modifying the regression function and increasing the variation of design parameters.
\end{abstract}

\section{INTRODUCTION}

There are some developments of technology to control storm water where it is generated, which is also known as source control. Some of them are sustainable urban drainage system (SUDS) that has been reviewed by some researchers (Belmeziti et al., 2015; Castro-Fresno et al., 2005; Charlesworth et al., 2003; Dierkes and Lucke, 2015; Kirby, 2005; Zhou, 2014), and low impact development (LID) that also has been studied by some experts (Ahiablame et al., 2012; Aungst, 2015; Fletcher et al., 2008, 2015, Guillette and Studio, 2005, 2010, Jia et al., 2012, 2013). Almost of review results agreed that urban storm water management should be handled concerning to sustainability of the resources. It is essential to control the resources closest to the source so that the impact does not spread out and the resource remains in the area.

Permeable pavement is a pavement technology which considers the efforts to control and conserve water resource where it is generated. There have been some researches on the hydraulic aspects of permeable pavement (Abbott and Comino-Mateos, 2003; Bentarzi et al., 2016), and the hydrological aspects of permeable pavement (Alsubih et al., 2016; Ball and Rankin, 2010; Bean et al., 2007; Drake et al., 2013; Scholz and
Grabowiecki, 2007). Concrete block pavement (CBP) is the most popular of permeable pavement technology. It is caused by the ability of the pavers to reduce surface runoff by its performance on infiltration and retarding the flow. There has been considerable studies on the physical characteristics of CBP and the infiltration performance, such as paving-block shape (Castro-Fresno et al., 2005; Lin et al., 2016), joint area between pavers and the clogging (Collins et al., 2008; Lucke, 2014; Yong et al., 2013), infiltration and water storage capacity of CBP (Borgwardt, 2006; González-Angullo et al., 2008; Lucke and Beecham, 2011; Park et al., 2014; WB Nichols et al., 2014). However, some studies performed contrary results compared to other studies concerning infiltration performance based on joint area (Collins et al., 2008), and slope gradient (Lucke and Beecham, 2011).

Previous studies have shown that there is no study that focused on investigation of CBP performance in retarding surface runoff related to its surface roughness. Surface roughness is an important parameter in generating the runoff velocity (Zhang et al., 2016). Therefore, this study aimed to present the effects of CBP physical properties on flow retardation factor.

*Corresponding author, e-mail: laksni.sedyowati@unmer.ac.id 


\section{MATERIALS AND METHODS}

\subsection{Concrete Block Pavement (CBP) Technology}

CBP is different from common concrete or asphalt pavements. It is constructed by using individual blocks or pavers with unique design patterns forming a grid surface layer to bear traffic loadings. The surface composition of CBP varies depending on the block shapes and construction patterns, so it is difficult to define a general equivalent surface roughness coefficient. Over the past two decades, there has been an amount of invention on CBP pattern.

A technology was performed to increase durability of CBP due to vehicle load. A square paver was made with a helical spline interlocking edge. The interlocking joint configurations permitted all edges of pavers to interlock. The interlocking joint would not only prevent vertical dislocation of pavers over time, but horizontal dislocation as well. The new interlocking can be applied to all of CBP pattern such as basket-weave, herringbone, stack bond, running bond, and hexagonal paver arrangement (Pollack, 2014). However, this kind of interlocking joint can reduce the space for water penetrating and reduce the surface roughness. Contrastingly, it was stated that block shapes did not have much effect on load distribution, whereas construction patterns did. Comparing with stretcherbond or basket-weave bond pattern, the herringbone bond pattern showed the best performance (Lin et al., 2016).

A new technology of CBP, namely tough water-permeable paver block, was developed by Hopperus-Buma (HopperusBuma, 2015). The paver comprises coated granules to make a continuous network of open spaces passing through the thickness of the paver. Coated granules lead to the joint filler materials more compact and tough in detaining the upper load and water flow. This technology can maintain the surface roughness of CBP without leaving the strength. However, the greater roughness of the CBP generated the higher contact pressure between tire and paving block compared to smooth surface (Yu et al., 2013). It was in contrary with the usage of CBP in decreasing surface runoff. Therefore, this study also tried to promote a practical solution that everyone can choose which CBP pattern will be used.

This study investigated four layers that was a combination of CBP shape and pattern, they were: 1) rectangular with basketweave pattern, 2) rectangular with 90 herringbone pattern, 3) tri-hexagonal blocks, and 4) hexagonal-hollow filled with sand. Each layer had three dimensionless parameters, namely openings ratio (Or), void ratio $(\mathrm{Vr})$ and straight channel ratio (Sr). Or and $\mathrm{Vr}$ has already known as attributes of CBP, however, the $\mathrm{Sr}$ was a relatively new parameter. The correlation of Sr to the flow retardant factor was examined in this study, individually and simultaneously with Or and Vr.

\subsection{Flow Retardation}

Concrete block pavement arrangement can establish a various pattern on the land surface. The texture formed by the pattern generates shear stress on the CBP surface that can retard the runoff velocity. A simulation model of pavement surface runoff has been developed by using flow resistance factor which was mainly caused by the texture of surface pavement (Wolff, 2013). The values obtained from the experiment also included other effects on flow resistance, like turbulence or shape resistance. Therefore, these effects were included indirectly in the resistance model. The friction slope was described by the Darcy-Weisbach equation. Small flow depth generated from the pavement surface led to the vertical change of the horizontal velocity components was very small so that the vertical velocity components were negligible.

A study on flow resistance on a boulder long chute (Pagliara et al., 2008) can be used as comparative study to quantify flow resistance values. The study was conducted in macro-roughness condition with or without boulders. The resistance coefficient was investigated by using relationship and dimensional analysis. Some conclusions have been undertaken, among others: 1) for the same relative submersion and percentage cover of boulders, the friction factor increases with an increase in slope; 2) for the same slope and relative submersion, the friction factor increases with an increase in the percentage cover of boulders; 3 ) an increase in the relative submersion leads to the decrease in the influence of boulders on friction factor; and 4) there are new proposed equations that show a good agreement with available data and extend the validity to different types of chutes include boulders.

Previous studies as mentioned above stated that CBP types influenced the infiltration performance, particularly the shape and the openings area of the pavers. The greater openings area could generate more infiltration. However, a research result concluded that a CBP surface that had a larger openings area generated more runoff than the smaller one (Collins et al., 2008). They mentioned that an area that was formed by the joint pavers from different CBP can lead to the decreasing in infiltration rate. From the illustration in their paper, it could be seen that the straight and longer channel generated more infiltration. On the other hand, infiltration will reduce the runoff and decrease the water depth on the CBP surface. In accordance to Boundary Layer Theory developed by L. Prandtl in 1904 (Schlichting and Gersten, 2017) and the result of Pagliara et al. (Pagliara et al., 2008), the flow velocity near the base is smaller than the flow velocity at the surface. It is caused by the surface roughness of the base.

Therefore, this study focused on the effects of CBP layers in retarding the flow, synthesised with the influence of various slope and rainfall intensity as well. The flow retardation coefficient was defined as a ratio which was quantified based on the difference in flow velocity on smooth pavement and CBP surface, then, was divided by the flow velocity on the smooth pavement. Therefore, the increase in flow retardation coefficient was equal to the decrease in flow velocity. A novel parameter was tried to explore concerning to the CBP layer and based on the Collins's result (Collins et al., 2008). The parameter was the straight channel ratio which was defined as a ratio between the frequent lengths of straight channel in one meter square CBP, and length of one meter. The unit was meter per meter $(\mathrm{m} / \mathrm{m})$.

\subsection{Experimental Program}

The experimental program was conducted on May 2016 until Pebruary 2017 which was experiencing a dry season and a rainy season. It was found a difficulty when was running experiment in the rainy season because the natural rainfall entered the test plot despite there was a roof above the plot. In order to keep the 
validity of the data, no experiment was undertaken when there was natural rain.

As shown in Figure 1, an experimental apparatus was built on a $179 \mathrm{~m}^{2}$ bare land in Malang City, Indonesia, in order to measure the effects of CBP pattern on the flow retardation factors. The apparatus was inspired by the experimental test rig developed by Lucke et al. (Lucke and Beecham, 2011). In this study, the apparatus consisted of a $2 \mathrm{~m} \mathrm{x} 6 \mathrm{~m}$ test plot which was laid on a platform. The platform height was $1.5 \mathrm{~m}$ above the ground to get variation of slope to maximum $25 \%$. The size was as the same as the test plot. In order to tilt the plot, each prop of the platform synthesised two perforated metal rod, therefore, they could be elevated and lowered according to the determined slope. Differed from the Lucke's test rig, in this study, the apparatus was also equipped by a rainfall simulator that consisted of five sprinklers for watering the entire plot area. The simulator has been analysed by using distribution uniformity (DU) method and coefficient of uniformity (CU) method. The results were DU $=81.4 \%$ and CU $=85.7 \%$. The simulation data were then verified by using natural rainfall data. The error was analysed by using Nash-Sutcliffe Efficiency (NSE), mean absolute error (MAE) and root mean square error (RMSE). The results were NSE $=89 \%$, MAE $=3 \%$, RMSE $=$ $8 \%$. It was concluded that the simulated rainfall was almost the same as the natural rainfall.

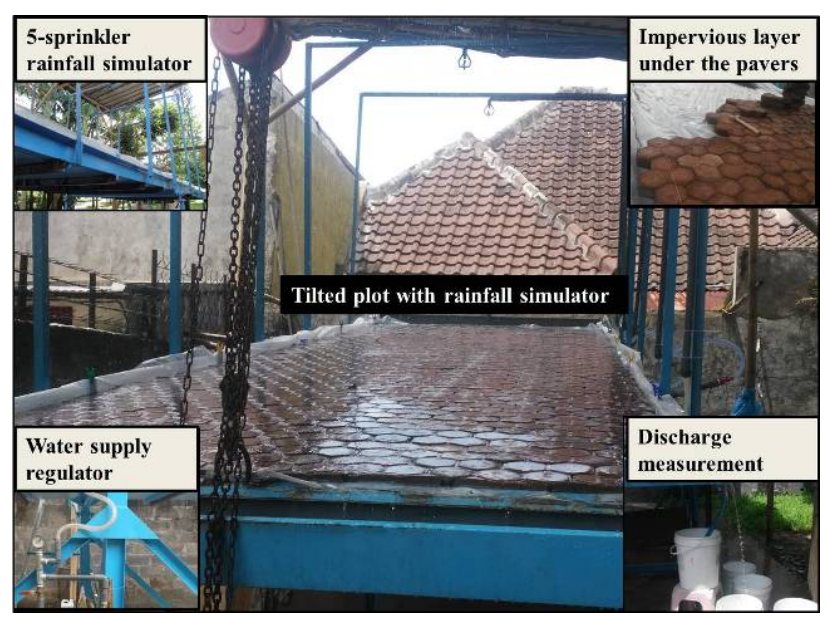

Figure 1. Experimental apparatus: test plot and 5-sprinkler rainfall simulator

First step of the experiment was measurement of the flow velocity on the smooth pavement by applying a set of slope and rainfall intensity. Afterwards, observations on four CBP layers with the same set of slope and rainfall intensity were undertaken. The layers consisted of hexagonal-hollow blocks, tri-hexagonal blocks, rectangular blocks and semi-porous rectangular blocks, as shown in Figure 2. To obtain a water saturated condition in the experimental process, the CBP layer was laid on an impermeable layer. This condition was required in generating an overland flow on the CBP surface. To drain the water that penetrated into the CBPs, there was a hole of $5 \mathrm{~cm}$ diameter at the bottom of the plot.

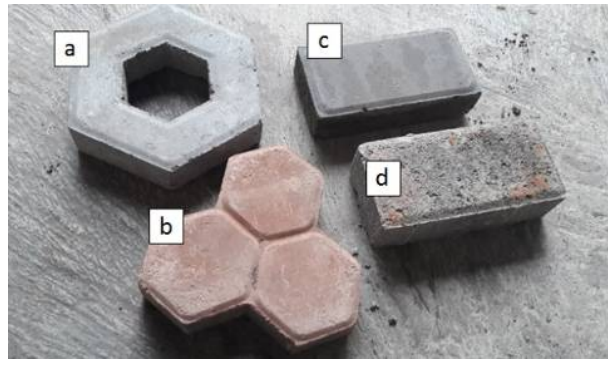

Figure 2. Four types of CBP: (a) hexagonal-hollow; (b) trihexagonal; (c) rectangular; (d) semi-porous rectangular

The experiment were conducted by using five design parameters and one observed value. The design parameters concerning the CBP layer comprised opening ratio (Or), void ratio $(\mathrm{Vr})$ and straight channel ratio $(\mathrm{Sr}) \mathrm{O}_{\mathrm{r}}$ was defined as the ratio between the total area of pavers joint in a $1-\mathrm{m}^{2}$ area and an area of $1 \mathrm{~m}^{2}\left(\mathrm{~m}^{2} / \mathrm{m}^{2}\right)$; Vr was the ratio between volume of water that infiltrated into the individual paver and the initial total volume $\left(\mathrm{m}^{3} / \mathrm{m}^{3}\right)$; and $\mathrm{Sr}$ was the ratio between frequent length of straight channel formed by pavers joint in a $1-\mathrm{m}^{2}$ paving block and a length of $1 \mathrm{~m}(\mathrm{~m} / \mathrm{m})$. The observed value was the flow retardation coefficient which was investigated through this experiment. The experiment was designed as follows: 1) the variation of slope gradient (S) consisted of 5\%, 10\% and 15\%; 2) the variation of rainfall intensity (I) consisted of $50 \mathrm{~mm} \cdot \mathrm{h}^{-1}$, $55 \mathrm{~mm} \cdot \mathrm{h}^{-1}$ and $60 \mathrm{~mm} \cdot \mathrm{h}^{-1}$; and 3) four kinds of CBPs as mentioned above.

The experiment was conducting with following procedure: 1) arranging the CBP pattern; 2) adjusting the slope gradient of the test plot; 3) watering the test plot with a defined rainfall intensity; 4) measuring the runoff discharge at the downstream section of the test plot; 5) performing dye-buoyant-oil tracing in view to quantify the travel time under rainfall after the discharge has been stable; 6 ) calculating the flow retardation coefficients based on the observed travel time; 7) interpreting data using MS Excel to define the correlation and determination coefficients $\left(\mathrm{R}^{2}\right)$, multivariate analysis of variance and regression function; 8) verifying the resulted model by using root mean square error (RMSE), mean absolute error (MAE) and Nash-Sutcliffe efficiency (NSE).

The dye-buoyant-oil tracing method was a modified method which synthesised the Dye Tracing Method and Float Method. Initially, a problem was appeared when only using the dye method. The raindrop splash caused the dye was dispersed. At the downstream end of the plot, the colour was not visible. Glitter powder was then used to replace the dye. Unfortunately, they cannot flow smoothly due to a constraint caused by the joint filler and the configuration of CBP. To overcome the problem, oil was applied to the test plot so that the glitter powder can float on oil and reach the downstream end.

\section{RESULTS AND DISCUSSION}

\subsection{Concrete Block Pavement (CBP) Properties}

Properties of CBP which was generated by shape and pattern of the pavers consist of opening ratio (Or), void ratio (Vr) and straight channel ratio (Sr). Table 1 represents the measurement results of Or, Vr and Sr. Each CBP layer has own characteristic which is mutually not relate. It is shown that there is no 
relationship between Or, Vr and Sr. A CBP that has a largest value on one property does not automatically have largest value on the others, and vice versa. For example, rectangular blocks has smallest Vr compared with other layers, but has greatest Sr. Hexagonal-hollow has greatest Or and Vr, but not for Sr. Trihexagonal blocks has smallest Sr but do not have any largest value.

\begin{tabular}{|c|l|c|c|c|}
\hline No & \multicolumn{1}{|c|}{ CBP Pattern } & Or & Vr & Sr \\
\hline 1 & Rectangular herringbone & 0.068 & 0.053 & 0.300 \\
2 & Tri-hexagonal blocks & 0.073 & 0.079 & 0.060 \\
3 & Hexagonal-hollow & 0.255 & 0.145 & 0.120 \\
4 & Rectangular basket-weave & 0.065 & 0.089 & 0.200 \\
\hline
\end{tabular}

Table 1. Values of opening ratio (Or) in $\mathrm{m}^{2} / \mathrm{m}^{2}$; void ratio (Vr) in $\mathrm{m}^{3} / \mathrm{m}^{3}$; straight channel ratio (Sr) in $\mathrm{m} / \mathrm{m}$

However, it can be noted that there is a similar trend of Or and $\mathrm{Vr}$ among each CBP layer, whereas the trend of Sr is different with other parameters, as shown in Figure 3. These trends can influence the correlation coefficients between those parameters and the flow retardation factor.

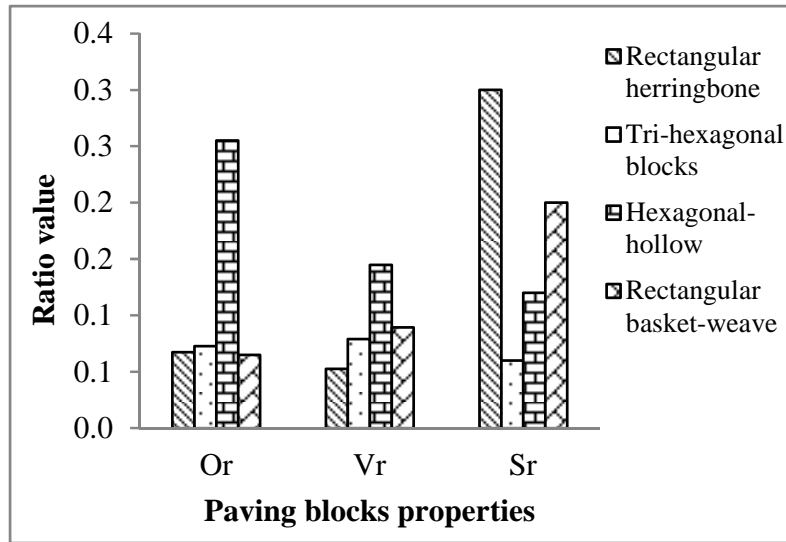

Figure 3. Variation of Or, Vr and Sr amongst CBP layers

Figure 3 indicates that rectangular blocks, tri-hexagonal blocks, and semi-porous rectangular blocks have similar Or despite their patterns were completely different. The difference of $\mathrm{Vr}$ values was caused by the difference of CBP materials which also could influence the surface roughness and infiltration rate. $\mathrm{Sr}$ in the rectangular blocks both smooth and semi-porous showed higher values than the others. A few difference values were led by the distinction of pattern that formed a straight channel at pavers joint. Smaller Sr at tri-hexagonal blocks and hexagonal hollow was impacted by the CBP shape that formed a shorter straight channel.

In general, a CBP layer has specific properties which can influence the flow retardation factor. Synthesising with other parameter such as slope and rainfall intensity can generate different result amongst the layers. It is required a deep analysis on flow retardation factor as a response of all predictor variables.

\subsection{Flow Retardation Coefficient}

Flow retardation coefficient was defined as a percentage of the decline in velocity between a smooth pavement and a CBP pavement. The greater flow retardation coefficient led to the decrease in velocity. As mentioned above, the flow retardation coefficient was calculated by dividing the difference in flow velocity on smooth pavement and CBP surface and the flow velocity on the smooth pavement. Table $2 \mathrm{a}$ and Table $2 \mathrm{~b}$ represent the decline of flow velocity and the flow retardation factor on the four layers of CBP, in meter per minute unit. Those data was obtained by applying the slope of $5 \%, 10 \%$, $15 \%$ and the rainfall intensity of $50 \mathrm{~mm} / \mathrm{h}, 55 \mathrm{~mm} / \mathrm{h}, 60 \mathrm{~mm} / \mathrm{h}$.

It can be shown that the largest flow velocity decline (3.29 $\mathrm{m} /$ minute) and the largest flow retardation coefficient (0.61) were on hexagonal hollow. It was certainly led by the sand filler in the hollow that retained more water. The smallest flow velocity decline $(2.35 \mathrm{~m} /$ minute $)$ and flow retardation coefficient $(0.37)$ was on rectangular herringbone, despite it had larger Or and Sr than rectangular basket-weave. The steeper slope led to more decrease in velocity and increase in flow retardation coefficient. Almost of the smallest decline and coefficient in all patterns was on the mild slope (5\%) and lowest rainfall intensity $(50 \mathrm{~mm} / \mathrm{h})$. However, the largest flow retardation coefficient (0.75) was on hexagonal hollow at the mildest slope (5\%) and highest rainfall intensity $(60 \mathrm{~mm} / \mathrm{h})$. It tends to be that the flow velocity decline and the flow retardation coefficient increases with an increase in the slope and rainfall intensity.

\begin{tabular}{|c|c|c|c|c|c|}
\hline \multirow{2}{*}{$\begin{array}{l}\text { Slope } \\
(\%)\end{array}$} & \multirow{2}{*}{$\begin{array}{c}\text { Rainfall } \\
\text { Intensity } \\
(\mathbf{m m} / \mathbf{h})\end{array}$} & \multicolumn{4}{|c|}{$\begin{array}{c}\text { Flow velocity decline } \\
\text { (m/minute) }\end{array}$} \\
\hline & & RH & TB & HH & $\mathbf{R B}$ \\
\hline 5 & 50 & 0.69 & 0.94 & 1.98 & 0.66 \\
\hline 5 & 55 & 0.76 & 1.27 & 2.23 & 0.99 \\
\hline 5 & 60 & 0.80 & 2.04 & 3.62 & 1.80 \\
\hline 10 & 50 & 1.18 & 1.18 & 2.10 & 0.93 \\
\hline 10 & 55 & 1.43 & 1.80 & 2.08 & 1.47 \\
\hline 10 & 60 & 2.62 & 3.01 & 3.35 & 2.75 \\
\hline 15 & 50 & 1.22 & 2.07 & 1.77 & 1.49 \\
\hline 15 & 55 & 5.36 & 6.04 & 5.45 & 5.41 \\
\hline 15 & 60 & 7.06 & 7.60 & 7.00 & 7.19 \\
\hline \multicolumn{2}{|c|}{ Average } & 2.35 & 2.88 & 3.29 & 2.52 \\
\hline
\end{tabular}

Note: $\quad R H=$ rectangular herringbone; $T B=$ tri-hexagonal blocks; $H H=$ hexagonal-hollow; $R B=$ rectangular basket-weave

Table 2a. Flow velocity decline on various CBP pattern, slope and rainfall intensity

\begin{tabular}{|c|c|c|c|c|c|}
\hline \multirow{2}{*}{$\begin{array}{c}\text { Slope } \\
\text { (\%) }\end{array}$} & \multirow{2}{*}{$\begin{array}{c}\text { Rainfall } \\
\text { Intensity }\end{array}$} & \multicolumn{3}{|c|}{ Flow retardation coefficient } \\
\cline { 3 - 6 } & $\mathbf{( m m} / \mathbf{h})$ & $\mathbf{R H}$ & $\mathbf{T B}$ & $\mathbf{H H}$ & $\mathbf{R B}$ \\
\hline 5 & 50 & 0.24 & 0.32 & 0.68 & 0.23 \\
5 & 55 & 0.22 & 0.37 & 0.66 & 0.29 \\
5 & 60 & 0.17 & 0.42 & 0.75 & 0.38 \\
\hline 10 & 50 & 0.34 & 0.34 & 0.61 & 0.27
\end{tabular}




\begin{tabular}{|l|l|l|l|l|l|}
10 & 55 & 0.34 & 0.43 & 0.49 & 0.35 \\
10 & 60 & 0.45 & 0.52 & 0.57 & 0.47 \\
\hline 15 & 50 & 0.28 & 0.48 & 0.41 & 0.34 \\
15 & 55 & 0.63 & 0.70 & 0.64 & 0.63 \\
15 & 60 & 0.67 & 0.72 & 0.66 & 0.68 \\
\hline \multicolumn{2}{|c|}{ Average } & 0.37 & 0.48 & 0.61 & 0.40 \\
\hline
\end{tabular}

Note: $\quad R H=$ rectangular herringbone; $T B=$ tri-hexagonal blocks; $H H=$ hexagonal-hollow; $R B=$ rectangular basket-weave

Table 2b. Flow retardation coefficients on various CBP pattern, slope and rainfall intensity

In order to better understand the response of each CBP pattern to the change in slope and rainfall intensity, the flow retardation factor was analysed as an individual response on a single design parameter and as simultaneous response of all design parameters.

\subsection{Design Parameter Analysis}

Based on the previous explanation, it can be identified that the response of CBP pattern to the change in slope and rainfall intensity was unique. Figure 4 describes that flow velocity decline (FVD) and flow retardation coefficient (FRC) increased with an increase in openings ratio and void ratio. Conversely, the increase in straight channel ratio led to a decrease in FVD and FRC. This phenomenon was in contrary with the Collin's research results (Collins et al., 2008). It was probably caused by the difference in defining the indicator. They only mentioned that the area between the individual concrete block was depressed and formed a channel which directed water into the gaps. In this study, the phenomenon was defined as straight channel ratio (Sr) which based on the length of the straight channel on the main direction of flow, as mentioned above.

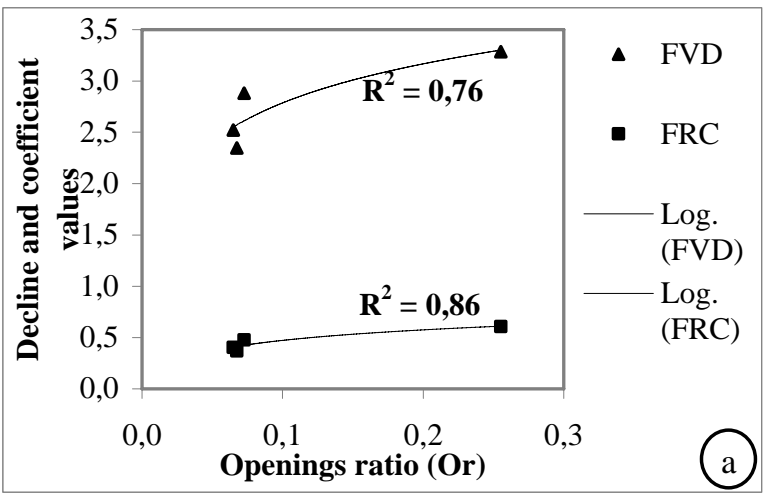

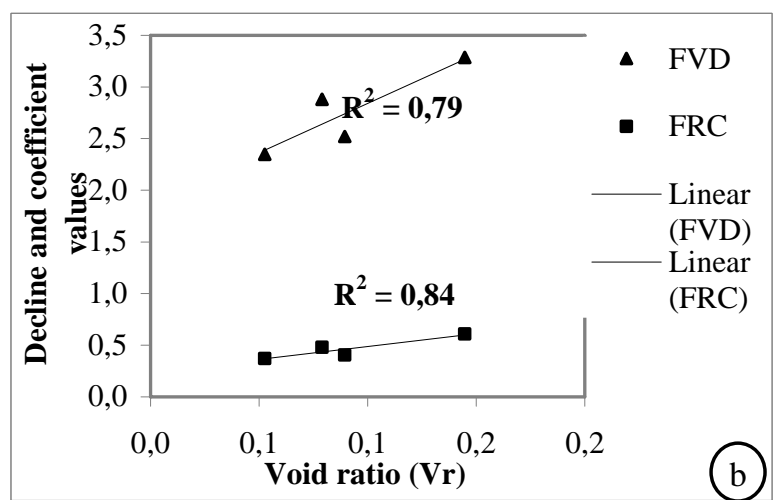

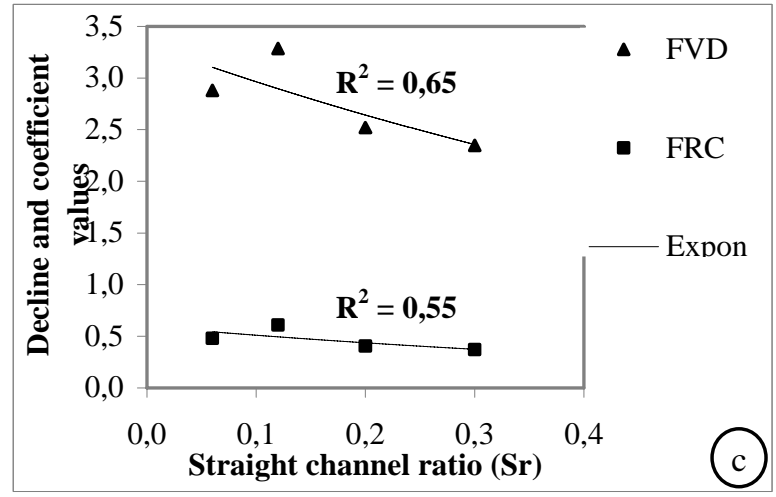

Figure 4. Relationship of average flow velocity decline (FVD); flow retardation coefficient (FRC), and: (a) openings ratio; (b) void ratio; (c) straight channel ratio

Table 3 presents the determination coefficient $\left(\mathrm{R}^{2}\right)$ between flow retardation coefficient (FRC) and CBP patterns, surface slope and rainfall intensity in various regression function. In rectangular herringbone pattern, the largest $R^{2}$ between the flow retardation coefficient and the surface slope was dominated by linear regression function. However, the largest $\mathrm{R}^{2}$ between the flow retardation coefficient and the rainfall intensity was dominated by power regression function. The average $R^{2}$ for linear and power function were respectively 0.80 and 0.73 . It is mean that the relationship amongst parameters could be assumed following the linear function.

\begin{tabular}{|c|c|c|c|c|c|}
\hline \multirow[t]{2}{*}{$\begin{array}{l}\text { Regression } \\
\text { function }\end{array}$} & \multicolumn{4}{|c|}{$\begin{array}{c}\mathrm{R}^{2} \text { of flow retardation coefficient } \\
\text { vs rainfall intensity }(\mathrm{mm} / \mathrm{h}) \text { in } \\
\text { average of various slope }(\%)\end{array}$} & \multirow[t]{2}{*}{ Average } \\
\hline & RH & TB & $\mathrm{HH}$ & $\mathrm{RB}$ & \\
\hline Linear & 0.81 & 0.93 & 0.51 & 0.95 & 0.80 \\
\hline Exponential & 0.80 & 0.93 & 0.49 & 0.94 & 0.79 \\
\hline Logarithmic & 0.80 & 0.94 & 0.51 & 0.95 & 0.80 \\
\hline Power & 0.79 & 0.94 & 0.50 & 0.95 & 0.80 \\
\hline Average & 0.80 & 0.94 & 0.50 & 0.95 & 0.80 \\
\hline \multirow[t]{2}{*}{$\begin{array}{c}\text { Regression } \\
\text { function }\end{array}$} & \multicolumn{4}{|c|}{$\begin{array}{l}\mathrm{R}^{2} \text { of flow retardation coefficient } \\
\text { vs surface slope (\%) in average of } \\
\text { various rainfall intensity }(\mathrm{mm} / \mathrm{h})\end{array}$} & \multirow[t]{2}{*}{ Average } \\
\hline & RH & TB & $\mathrm{HH}$ & $\mathrm{RB}$ & \\
\hline Linear & 0.70 & 0.89 & 0.39 & 0.94 & 0.73 \\
\hline Exponential & 0.72 & 0.92 & 0.37 & 0.96 & 0.74 \\
\hline Logarithmic & 0.72 & 0.79 & 0.45 & 0.85 & 0.70 \\
\hline
\end{tabular}




\begin{tabular}{|l|l|l|l|l|l|} 
Power & 0.76 & 0.82 & 0.40 & 0.89 & 0.72 \\
\hline Average & 0.73 & 0.86 & 0.40 & 0.91 & 0.72 \\
\hline
\end{tabular}

Note: $\quad R H=$ rectangular herringbone; $T B=$ tri-hexagonal blocks; $\mathrm{HH}=$ hexagonal-hollow; $\mathrm{RB}=$ rectangular basket-weave

Table 3. Determination coefficients $\left(\mathrm{R}^{2}\right)$ between FRC and slope; and rainfall intensity on rectagular basket-weave pattern

Table 3 also indicates that the relationship between flow retardation coefficient and the surface slope on rectangular basket-weave pattern and tri-hexagonal were dominated by linear regression function. Whereas the relationship between flow retardation coefficient and rainfall intensity was dominated by exponential function. Hexagonal-hollow layer showed the lowest $\mathrm{R}^{2}$, particularly in slope of $10 \%$ and rainfall intensity of $55 \mathrm{~mm} / \mathrm{h}$. It was probably caused by other parameters which were not previously identified such as the properties of sand filling, the diameter of hollow, etc.

However, in general, rainfall intensity and surface slope significantly influenced the flow retardation factor. The increase in rainfall intensity lead to the water in the channel formed by the paver joint more depressed. Therefore, more water was penetrated into the paving block layer. It was in agreement with the result of Collins et al. (Collins et al., 2008).

The increase in surface slope led to the increase in flow retardation coefficient which was expressed by a linear regression function. It was in agreement with the result of Pagliara et al. (Pagliara et al., 2008) which was undertaken on a boulder long chute. As shown in Table 2, the flow retardation factor increased with an increase in slope. It was probably caused by the greater flow velocity with a large energy led to more water penetrated into the void.

Table 3 also shows that the influence of rainfall intensity and the surface slope on flow retardation factor was almost the same, based on average $\mathrm{R}^{2}$ of each various slope and rainfall intensity. It can be seen that the average of $\mathrm{R}^{2}$ of the rainfall intensity (0.80) was not much different from the surface slope (0.72) in entire CBP patterns.

Figure 5a-d describes that the performance of rectangular basket-weave pattern and tri-hexagonal blocks in retarding the flow were almost the same. The flow retardation increased with an increase in rainfall intensity and surface slope. In steep slope (15\%), there was more increase in flow retardation compared to other slope. However, the performance of rectangular herringbone particularly in slope of $5 \%$ was rather different. There was a negative correlation between flow retardation coefficient and rainfall intensity. In this condition, rainfall intensity was probably greater than water penetration rate so that there was more water on the surface that generating more surface runoff, despite the Sr was greater than the others. In accordance to Collins's result (Collins et al., 2008) as mentioned above, the longer straight channel supposed to lead a greater infiltration, but it did not. Therefore, it concluded that the Collins's result was inapplicable in mild slope such as $5 \%$. Figure 5 (d) shows that in hexagonal-hollow almost of all design parameters did not significantly influence the flow retardation coefficient. It was likely caused by the difference in surface configuration and geometry of the CBP.

\subsection{Statistical Analysis}

The relationship of CBP properties (consist of Or, Vr, Sr) synthesised with $\mathrm{S}$ and $\mathrm{D} / \mathrm{Dm}$ was conducted by using analysis of variance (ANOVA). A ratio of raindrop diameter, namely D/Dm was promoted instead of rainfall intensity (I) to get dimensionless parameter. A multiple linear regression analysis was used in accordance to the relationship between parameters as shown in Figure 5 above.

The statistical analysis resulted as follows: 1) Multiple $\mathrm{R}=$ 0.80 , it means that the relation between dependent variable and all independent variables simultaneously was $80 \%$ significant; 2) R square $=0.63$, it means that proportion of total variance in dependent variable that explained by independent variables was $63 \%$; 3) Standard error $=0.11$, it means that the linear regression model performed $11 \%$ error in predicting the dependent variable. Therefore, the use of the linear regression model was good in predicting the flow retardation coefficient by considering the error rate $(11 \%)$ and the determination coefficient (63\%).

Level of acceptability the linear model which was examined by using ANOVA can be explained as follows: 1) SS of regression $=0.64$ and SS of residual $=0.37$, it means that about $64 \%$ variance of flow retardation coefficient was influenced by the dependent variables, whilst $37 \%$ was caused by other variables that also affect but was not included in the model (residual); 2) $\mathrm{F}=10.4>\mathrm{F}$ table $=2.5$ and $\mathrm{P}<0.01$, it means that Or, Vr, Sr, S and $\mathrm{D} / \mathrm{Dm}$ significantly influenced the flow retardation coefficient.

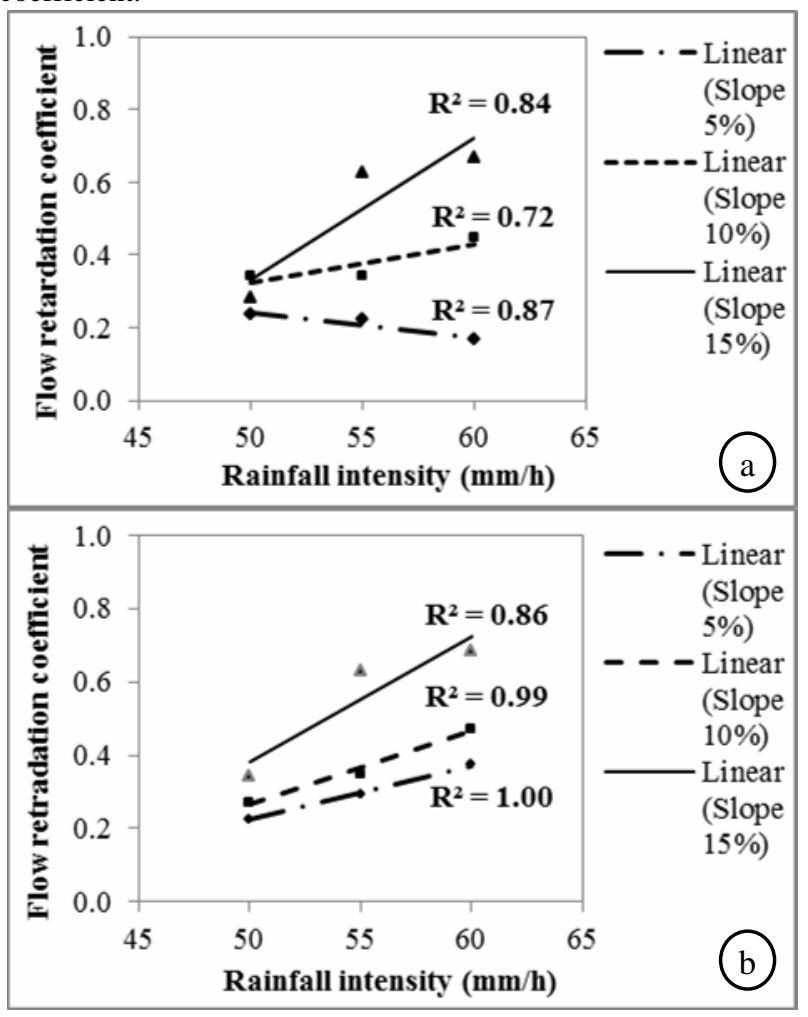




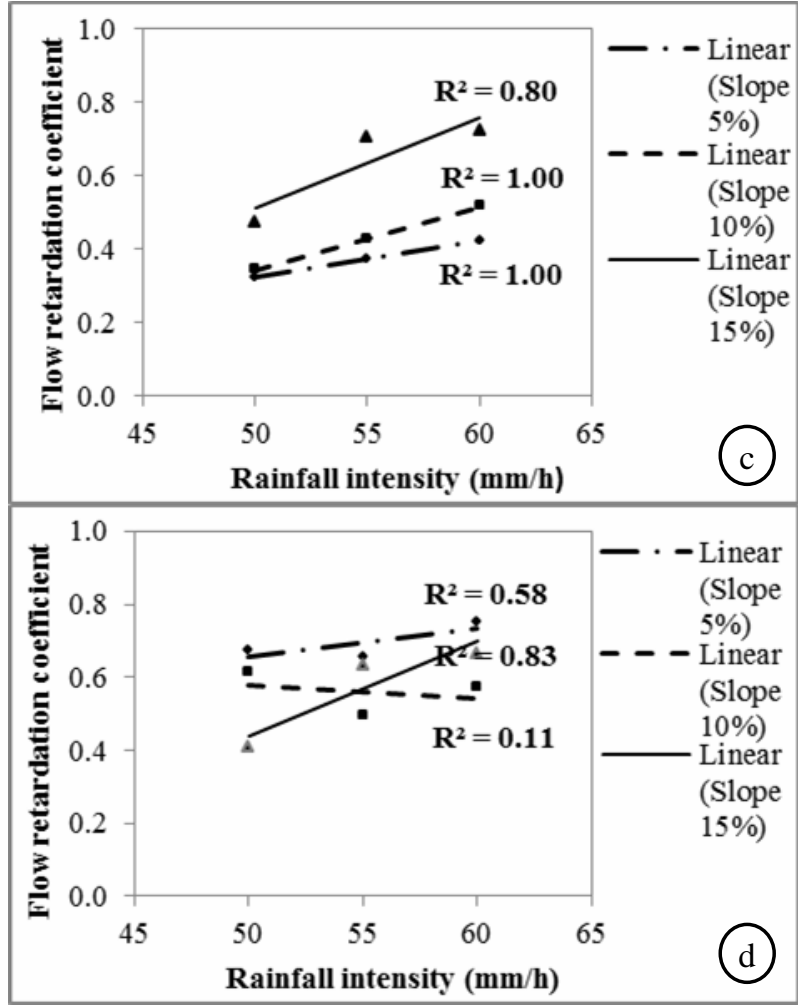

Figure 5. Linear relationship of rainfall intensity and flow retardation coefficient based on various slope on: (a) rectangular herringbone; (b) rectangular basket-weave; (c) trihexagonal blocks; (d) hexagonal-hollow

According to the previous explanation, the relationship between the flow retardation coefficient and the design parameters was expressed by a linear equation model as shown in Equation 1, as follow:

$$
F_{r d}=0.55+\left(0.95 O_{r}\right)-\left(0.26 V_{r}\right)-\left(0.46 S_{r}\right)+(0.02 S)-\left(0.27 \frac{D}{D_{m}}\right)
$$

where Frd $=$ flow retardation coefficient

Or $=$ openings ratio

$\mathrm{Vr}=$ void ratio

$\mathrm{Sr}=$ straight channel ratio

$\mathrm{S}=$ surface slope

$\mathrm{D}=$ diameter of raindrop $(\mathrm{mm})$

$\mathrm{Dm}=$ mean diameter of raindrop $(\mathrm{mm})$

The model was then examined by using root mean square error (RMSE), mean absolute error (MAE) and Nash-Sutcliffe efficiency (NSE). The results were RMSE $=10 \%$; MAE $=8 \%$; $\mathrm{NSE}=63 \%$. It seems that the model needs further development because there were probably other predictor parameters that have not been identified, so that a model with strong relationship and high accuracy can be achieved.

However, this study found that the increase in surface slope of CBP pavement can decrease the runoff velocity and delay the flow reaching the closest channel. Few different results were performed on the change in rainfall intensity. In some conditions showed that the increase in the rainfall intensity led to an increase in the flow retardation and flow velocity, however, at the mild slope, the flow retardation decreased with an increase in rainfall intensity. These results, particularly the response to the surface slope, were in contrast compared to observation data conducted in a smooth pavement, but showed a good agreement with Pagliara et al. (2008).

\section{CONCLUSION}

The shape of concrete block pavement (CBP) did not significantly lead to the difference in the opening ratio which is the important parameter related to infiltration rate. The use of CBP layer could be more effective in retarding the flow by considering the arrangement of CBP pattern that synthesised with surface slope. The effects of CBP patterns on the flow velocity in various surface slope and rainfall intensity were unique. The flow velocity decline and flow retardation coefficient increased with an increase in openings ratio, rainfall intensity and surface slope. Conversely, the increase in void ratio, straight channel ratio and raindrop size led to a reduction in flow velocity decline and flow retardation coefficient. However, there was an exception in rectangular herringbone (slope 5\%) and hexagonal-hollow (slope 10\%), where the increase in rainfall intensity did not lead to an increase in flow retardation coefficient.

A model of flow retardation coefficient was developed based on linear regression function. The model can predict flow retardation coefficient on CBP layer when the CBP properties (openings ratio, void ratio, straight channel ratio), surface slope and raindrop diameter were known.

However, a further study is required to improve the performance of the model by using a multiple non-linear regression analysis. That study is expected to strengthen the relationship amongst the parameters, and to identify other predictor parameters in increasing the accuracy of the model.

\section{ACKNOWLEDGEMENTS}

We would like to thank to the people who have assisted in conducting this research, especially the students of Civil Engineering Department, University of Merdeka Malang. This research was financially supported by The Ministry of Research, Technology and Higher Education, Republic of Indonesia, through research grant namely Penelitian Hibah Bersaing (PHB) 2016-2017.

\section{REFERENCES}

Abbott, C.L., Comino-Mateos, L., 2003. In-situ hydraulic performance of a permeable pavement sustainable urban drainage system. Water Environ. J. 17, 187-190.

Ahiablame, L.M., Engel, B.A., Chaubey, I., 2012. Effectiveness of low impact development practices: literature review and suggestions for future research. Water. Air. Soil Pollut. 223, 4253-4273.

http://link.springer.com/article/10.1007/s11270-012-1189-2.

Alsubih, M., Arthur, S., Wright, G., Allen, D., 2016. Experimental study on the hydrological performance of a permeable pavement. Urban Water J. 1-8, http://dx.doi.org/10.1080/1573062X.2016.1176221. 
Aungst, P.E., 2015. Coupling Stormflow Attenuation with Gully and Trail Stabilization, Wissahickon Valley Park, Philadelphia. Low Impact Dev. Technol. 208.

http://ascelibrary.org/doi/pdfplus/10.1061/9780784413883\#pag $\mathrm{e}=219$.

Ball, J.E., Rankin, K., 2010. The hydrological performance of a permeable pavement. Urban Water J. 7, 79-90.

http://www.tandfonline.com/doi/abs/10.1080/15730620902969 773.

Bean, E.Z., Hunt, W.F., Bidelspach, D.A., 2007. Field survey of permeable pavement surface infiltration rates. J. Irrig. Drain. Eng. 133, 249-255.

http://ascelibrary.org/doi/abs/10.1061/(ASCE)07339437(2007)133:3(249).

Belmeziti, A., Cherqui, F., Tourne, A., Granger, D., Werey, C., Le Gauffre, P., Chocat, B., 2015. Transitioning to sustainable urban water management systems: how to define expected service functions? Civ. Eng. Environ. Syst. 32, 316-334. http://www.tandfonline.com/doi/abs/10.1080/10286608.2015.1 047355 .

Bentarzi, Y., Ghenaim, A., Terfous, A., Wanko, A., Feugeas, F., Poulet, J.-B., Mosé, R., 2016. Hydrodynamic behaviour of a new permeable pavement material under high rainfall conditions. Urban Water J. 13, 687-696.

http://iahr.tandfonline.com/doi/abs/10.1080/1573062X.2015.10 24688.

Borgwardt, S., 2006. Long-term in-situ infiltration performance of permeable concrete block pavement, in: Proceedings of the 8th International Conference on Concrete Block Paving, San Francisco, CA, USA.

Castro-Fresno, D., Rodriguez-Hernandez, J., RodriguezHernandez, J., Ballester-Munoz, F., 2005. Sustainable Urban Drainage Systems (SUDS). Interciencia 30, 255.

Charlesworth, S.M., Harker, E., Rickard, S., 2003. A review of sustainable drainage systems (SuDS): A soft option for hard drainage questions? Geography 99-107.

http://www.jstor.org/stable/40573828.

Collins, K.A., Hunt, W.F., Hathaway, J.M., 2008. Hydrologic comparison of four types of permeable pavement and standard asphalt in eastern North Carolina. J. Hydrol. Eng. 13, 11461157.

http://ascelibrary.org/doi/abs/10.1061/(ASCE)10840699(2008)13:12(1146).

Dierkes, C., Lucke, T., 2015. Development and approval of an innovative permeable pavement with high design demands, in: Proceedings of the 36th International Association for HydroEnvironment Engineering and Research World Congress. International Association for Hydro-Environment Engineering and Research, pp. 1-8.

Drake, J.A., Bradford, A., Marsalek, J., 2013. Review of environmental performance of permeable pavement systems: state of the knowledge. Water Qual. Res. J. Can. 48, 203-222.

Fletcher, T.D., Deletic, A., Mitchell, V.G., Hatt, B.E., 2008. Reuse of urban runoff in Australia: a review of recent advances and remaining challenges. J. Environ. Qual. 37, S-116.

Fletcher, T.D., Shuster, W., Hunt, W.F., Ashley, R., Butler, D., Arthur, S., Trowsdale, S., Barraud, S., Semadeni-Davies, A.,
Bertrand-Krajewski, J.-L., others, 2015. SUDS, LID, BMPs, WSUD and more-The evolution and application of terminology surrounding urban drainage. Urban Water J. 12, 525-542. http://iahr.tandfonline.com/doi/abs/10.1080/1573062X.2014.91 6314.

González-Angullo, N., Castro, D., Rodríguez-Hernández, J., Davies, J.W., 2008. Runoff infiltration to permeable paving in clogged conditions. Urban Water J. 5, 117-124. http://www.tandfonline.com/doi/abs/10.1080/15730620701723 538.

Guillette, A., Studio, L.I.D., 2010. Achieving Sustainable Site Design through Low Impact Development Practices. Whole Build. Des. Guide Www Wbdg Org.

Guillette, A., Studio, L.I.D., 2005. Low impact development technologies. National Institute of Building Sciences.

Hopperus-Buma, P.B., 2015. Tough, water-permeable paver. Google Patents.

Jia, H., Lu, Y., Shaw, L.Y., Chen, Y., 2012. Planning of LIDBMPs for urban runoff control: The case of Beijing Olympic Village. Sep. Purif. Technol. 84, 112-119.

http://www.sciencedirect.com/science/article/pii/S13835866110 02504

Jia, H., Yao, H., Shaw, L.Y., 2013. Advances in LID BMPs research and practice for urban runoff control in China. Front. Environ. Sci. Eng. 7, 709-720.

http://link.springer.com/article/10.1007/s11783-013-0557-5.

Kirby, A., 2005. SuDS- innovation or a tried and tested practice?, in: Proceedings of the Institution of Civil EngineersMunicipal Engineer. London: Published for the Institution of Civil Engineers by Thomas Telford Services, c1992-, pp. 115122.

Lin, W., Cho, Y., Kim, I.T., 2016. Development of Deflection Prediction Model for Concrete Block Pavement Considering the Block Shapes and Construction Patterns. Adv. Mater. Sci. Eng. 2016.

https://www.hindawi.com/journals/amse/2016/5126436/abs/.

Lucke, T., 2014. Using drainage slots in permeable paving blocks to delay the effects of clogging: Proof of concept study. Water 6, 2660-2670.

http://www.mdpi.com/2073-4441/6/9/2660/htm.

Lucke, T., Beecham, S., 2011. An investigation into long term infiltration rates for permeable pavements on sloping subcatchments, in: 12th International Conference on Urban Drainage, Brazil.

Pagliara, S., Das, R., Carnacina, I., 2008. Flow resistance in large-scale roughness condition. Can. J. Civ. Eng. 35, 12851293.

http://www.nrcresearchpress.com/doi/abs/10.1139/108-068

Park, D.-G., Sandoval, N., Lin, W., Kim, H., Cho, Y.-H., 2014. A case study: Evaluation of water storage capacity in permeable block pavement. KSCE J. Civ. Eng. 18, 514-520.

http://link.springer.com/article/10.1007/s12205-014-0036-y.

Pollack, R., 2014. Interlocking construction systems and methods. Google Patents. 
Schlichting, H., Gersten, K., 2017. Fundamentals of BoundaryLayer Theory, in: Boundary-Layer Theory. Springer, pp. 2949.

http://link.springer.com/chapter/10.1007/978-3-662-52919-5_2.

Scholz, M., Grabowiecki, P., 2007. Review of permeable pavement systems. Build. Environ. 42, 3830-3836.

http://www.sciencedirect.com/science/article/pii/S03601323060

04227.

WB Nichols, P., Lucke, T., Dierkes, C., 2014. Comparing two methods of determining infiltration rates of permeable interlocking concrete pavers. Water 6, 2353-2366.

http://www.mdpi.com/2073-4441/6/8/2353/htm.

Wolff, A., 2013. Simulation of pavement surface runoff using the depth-averaged shallow water equations. http://elib.uni-stuttgart.de/handle/11682/505.

Yong, C.F., McCarthy, D.T., Deletic, A., 2013. Predicting physical clogging of porous and permeable pavements. J. Hydrol. 481, 48-55.

http://www.sciencedirect.com/science/article/pii/S00221694120 10694.

Yu, C.C., Chang, J.W., Hao, S.W., 2013. A Numerical Method for the Paving Block Evaluation, in: Applied Mechanics and Materials. Trans Tech Publ, pp. 524-528.

http://www.scientific.net/AMM.395-396.524.

Zhang, S., Liu, Y., Li, M., Liang, B., 2016. Distributed hydrological models for addressing effects of spatial variability of roughness on overland flow. Water Sci. Eng. 9, 249-255. http://www.sciencedirect.com/science/article/pii/S16742370163 00205.

Zhou, Q., 2014. A review of sustainable urban drainage systems considering the climate change and urbanization impacts. Water 6, 976-992.

http://www.mdpi.com/2073-4441/6/4/976/htm. 